\title{
ANÁLISE E ESPACIALIZAÇÃO DA INCIDÊNCIA DE DENGUE NA MICRORREGIÃO GEOGRÁFICA DE ANÁPOLIS-GO, PERÍODO DE 2010-2016
}

\author{
ANALYSIS AND SPACIATIZATION OF DENGUE FEVER IN THE GEOGRAPHICAL \\ MICROREGION OF ANÁPOLIS-GO, PERIOD OF 2010-2016
}

\author{
Fernando Honorato Nascimento \\ Mestre em Química, Instituto Federal Goiano \\ fhnquimica@yahoo.com.br \\ Leonardo Batista Pedroso \\ Mestre em Geografia, Instituto Federal Goiano \\ leonardo.pedroso@ifgoiano.edu.br
}

\begin{abstract}
RESUMO
A dengue é concebida como um dos principais desafios da saúde pública mundial. Objetivou-se analisar a incidência da dengue na microrregião geográfica de Anápolis, Estado de Goiás, Brasil; para o período que compreende os anos entre 2010 e 2016 Realizou-se uma pesquisa observacional, quantitativa, descritiva e exploratória. Foram obtidos dados junto à Superintendência de Vigilância em Saúde da Secretaria de Estado da Saúde do Governo do Estado de Goiás - SES-GO, ligada também ao Banco de Dados do Sistema Único de Saúde - DATASUS. Os dados compreendem as manifestações clínicas da dengue registradas no CID-10, sendo elas: Dengue Clássica, Febre Hemorrágica de Dengue e Dengue com Complicações. O coeficiente de incidência de dengue para os municípios foi calculado, permitindo a estratificação em classes de frequência, conforme recomendação da Organização Mundial da Saúde - OMS, adicionando-se uma categoria, relativa às "altíssimas incidências". A Microrregião de Anápolis chegou a apresentar 17.400 casos no ano de 2016. Os resultados demonstraram que a dengue se comportou de maneiras distintas entre os anos de 2010 e 2016. Durante todo o período analisado, os dados acusam situação epidêmica, isto é, com coeficientes muito acima dos limites considerados dentro do padrão de controle e/ou normalidade da OMS. A análise da situação da dengue na Microrregião de Anápolis revela um grave problema de saúde pública para a grande maioria dos municípios presentes na área de estudo, o que demonstra a importância da observação pelos gestores de saúde de que os altíssimos índices registrados endossam a necessidade de reavaliar políticas e métodos de controle da doença e do vetor.
\end{abstract}

Palavras-chave: Dengue. Microrregião de Anápolis. Incidência.

\begin{abstract}
The dengue fever is understood as one of the mainly challenges of global public health. Was aimed analyze the incidence of dengue fever in the geographical microregion of Anápolis, State of Goiás, Brazil; to the period between the years of 2010 and 2016. Was realized an observational, quantitative, descriptive and exploratory research. Were obtained data from the Superintendence of Health Surveillance of the Secretary of State for Health of the Government of the State of Goiás - SES-GO, also linked to the Single System of Health Database - DATASUS. The data include the clinical manifestations of dengue fever recorded in ICD-10, being them: Classical Dengue, Dengue Hemorrhagic Fever and Dengue with Complications. The dengue fever incidence coefficient to the cities was calculated allowing the stratification in frequency classes, according recommendation of the World Health Organization - WHO, adding a category, relating to the "very high incidence". The Microregion of Annapolis presented 17.400 cases in the year of 2016. The results demonstrated that the dengue fever behaved differently between the years 2010 and 2016 . During the analyzed period, the data accuses an epidemic situation, with coefficients well above the limits considered within the control pattern and/or normality of WHO. The analysis of the dengue situation in the Microregion of Annapolis reveals a serious public health
\end{abstract}


problem for the great majority of cities present in the study area, demonstrating the importance of the observation by the health managers that the extremely high

indexes registered endorsed the needing to re-evaluate policies and methods of disease and vector control.

Keywords: Dengue Fever. Microregion of Anápolis. Incidence.

\section{INTRODUÇÃO}

$\mathrm{Na}$ contemporaneidade, diferentes trabalhos acadêmicos visam abordar a temática da qualidade de vida atrelada à aspectos de saúde. Isto se deve ao fato do aumento considerável na incidência de diferentes tipos de doenças, como consequência da mudança do perfil e no estilo de vida, observados em países de diferentes níveis socioeconômicos. Essas mudanças pressionam os órgãos e gestores públicos de saúde ao desenvolvimento de políticas públicas, em especial, voltadas a prevenção de doenças e promoção da saúde (SEIDL, ZANNON, 2004).

Não obstante à tais mudanças, a sociedade passa também por uma constante reconfiguração espacial, oriunda de processos como a urbanização, em muitos casos, desordenada e acelerada, resultando em infraestruturas urbanas inadequadas, como as péssimas condições da infraestrutura sanitária, ocasionando o aumento significativo de problemas relacionados à saúde pública. Quando tal fenômeno ocorre, é complexo estabelecer um equilíbrio entre o crescimento urbano e a saúde pública. Assim sendo, a influência do meio e as relações sociais também são pontos marcantes enquanto determinantes sociais de saúde, sendo elementos que podem induzir a estratificação social, estando motivada pela distribuição desigual relativa a fatores de ordem material, psicossocial e biológica (ZIONI, WESTPHAL, 2007; SOUZA, 2008).

A dengue, diante deste contexto, é concebida como um dos principais desafios da saúde pública mundial, gerando prejuízos significativos para as populações de diferentes países afetados, seja na perspectiva da saúde e qualidade de vida, como nos aspectos econômicos. Estima-se que a doença atinja entre 50 e 80 milhões de pessoas por ano, distribuídas em mais de 125 países das regiões tropicais e subtropicais do planeta, cuja ocorrência se dá de forma endêmica. Tais áreas concentram quase $40 \%$ da população mundial que vivem expostas a infecção por esse vírus, constituindo-se, portanto, em um dos mais sérios problemas de saúde pública do mundo, sobretudo em países da África, Ásia e América situados em regiões intertropicais (QUEIROZ, 2016; MENDONÇA, SOUZA e DUTRA, 2009; PEDROSO, MENDES e MOURA, 2012; WHO, 2012).

Assim, pela abrangência e adaptabilidade do vetor Aedes aegypti (Ae. Aegypti), a dengue é a mais prevalente infecção viral causada por um vetor, causando epidemias, morte e prejuízos nos países por ela acometidos (QUEIROZ, 2016).

Trata-se de infecção viral transmitida por meio da picada de mosquitos fêmeas infectados do gênero Aedes, existindo quatro sorotipos virais do dengue, sendo eles DEN 1, DEN 2, DEN 3 e DEN 4. Os sintomas surgem entre 3 e 14 dias (em média de 4 a 7 dias) após a picada infecciosa. A dengue é uma doença muito similar a gripe e que afeta lactentes, crianças pequenas e os adultos (OMS, 2016).

Somente as fêmeas de Ae. Aegypti necessitam de sangue humano, designado para maturação dos ovos. Tanto o macho quanto a fêmea se alimentam de substâncias açucaradas presentes nas flores, no entanto, somente a fêmea dispõe de hábito antropofílico. Essa espécie é considerada sinantrópica e bem adaptada ao ambiente urbano (GOMES, 2016).

Em 2016, foram registrados mais de 800 mil casos prováveis de dengue no Brasil, com 140 óbitos. O Ae. aegypti é o vetor do vírus que pode ocasionar a febre amarela urbana; a doença foi controlada nas cidades durante determinado período, ocorrendo somente em sua forma silvestre. Hoje, jornais noticiam reincidência em áreas urbanas no Brasil (QUEIROZ, 2016).

A dengue está fortemente relacionada com as variáveis meteorológicas devido à aspectos relacionados à adaptabilidade vetorial. A variação sazonal da temperatura e da pluviosidade influenciam a dinâmica do vetor e a incidência da doença em todo o país (VIANA \& IGNOTTI, 2013).

Dessa forma, pode-se observar que mesmo diante das características naturais e antrópicas que favorecem a dispersão da doença, constatou-se nos últimos anos uma alteração significativa nos 
aspectos epidemiológicos, sobretudo no que se refere a abrangência espacial dos casos. A dengue deixou de ser uma doença exclusiva das regiões tropicais (PEDROSO, MENDES, MOURA, 2012).

Estudos voltados à investigação dos fatores determinantes da distribuição espacial da dengue devem ser considerados como ferramenta de gestão para micro e mesorregiões assistenciais de saúde, as quais podem analisar mais detalhadamente as carências e particularidades de seus municípios e, assim, desenvolver um planejamento e gestão em saúde mais eficiente, seja ele voltado a ações curativas, preventivas ou de promoção (PEDROSO, MENDES, MOURA, 2012).

A partir da análise de incidência de casos prováveis de dengue, segundo regiões geográficas, observou-se que as regiões Centro-Oeste e Sudeste apresentam as maiores incidências: 1.451,9 casos/100 mil hab. e 1.205,7 casos/100 mil hab., respectivamente. Entre os estados, destacam-se Goiás (2.500,6 casos/100 mil hab.) e São Paulo (1.665,7 casos/100 mil hab.) (BRASIL, 2016).

Diante deste cenário, fazem-se necessárias pesquisas que abordem a dengue e as variáveis inerentes à mesma, relacionando-a à diferentes aspectos que possam favorecer o aumento do número de casos. O objetivo deste trabalho é analisar a incidência da dengue na microrregião geográfica de Anápolis, Goiás, para o período que compreende os anos entre 2010 e 2016.

A partir deste objetivo, este artigo dispõe de três seções após a introdução: a primeira relativa à fundamentação teórica, que apresenta uma breve caracterização histórico-geográfica da dengue e de seu principal vetor; a segunda que aborda a metodologia utilizada para a realização do trabalho; a terceira, apresentando os resultados e discussões sobre os dados obtidos. Após tais seções, são apresentadas considerações finais e referências utilizadas para a produção do trabalho.

\section{BREVE CARACTERIZAÇÃO HISTÓRICO-GEOGRÁFICA DA DOENÇA E DO VETOR}

A raiz etimológica da palavra dengue tem origem espanhola e quer dizer "melindre", "manha". Portanto, o nome faz referência ao estado de moleza e prostração em que fica o indivíduo contaminado pelo arbovírus. Arbovírus é a abreviatura do inglês de arthropod-bornvirus, vírus oriundo dos artrópodos. O mosquito transmissor da dengue foi introduzido na América do Sul através de barcos, chamados de navios negreiros. Estes barcos provenientes da África, que no período colonial brasileiro, traziam os escravos. Houve casos em que os barcos ficaram com a tripulação tão reduzida que passaram a vagar pelos mares, constituindo os chamados "navios-fantasmas" (BRASIL, 2016).

O Aedes aegypti é reconhecível pela sua cor preta, pernas rajadas e pintas brancas. É original do norte da África, onde ocupava originalmente florestas. Seu nome significa "o odioso do Egito" (aedes vem do grego e aegypti, do latim). Era inicialmente encontrado nas florestas do norte da África e picava primatas na mata; aos poucos se adaptou para viver nas proximidades das comunidades humanas. Com o aumento da circulação de pessoas e bens de várias partes do mundo, o mosquito também se disseminou. Chegou às Américas por meio dos navios negreiros. Os primeiros registros de febre amarela nas Américas são do século XVII (GOMES, 2016).

A dengue é conhecida no Brasil desde os tempos de colônia. O primeiro caso da doença foi registrado em 1685, em Recife no estado de Pernambuco. Em 1692, a dengue provocou 2 mil mortes em Salvador (BA), e reemergiu em um novo surto em 1792. Em 1846, o mosquito Ae. aegypti tornouse conhecido quando uma epidemia de dengue atingiu os estados do Rio de Janeiro, São Paulo e a cidade de Salvador (BA). Entre 1851 e 1853 e em 1916, a cidade São Paulo foi atingida por epidemias da doença (QUEIROZ, 2016).

A distribuição geográfica dos mosquitos vetores e os vírus contribuíram para o ressurgimento da epidemia global de dengue e o aparecimento da febre hemorrágica da dengue (FHD) nos últimos 25 anos. Desde o ano de 1980, o tema da dengue é frequente também na mídia brasileira, com espaço garantido nas manchetes a cada emergência sazonal da doença, normalmente a cada ano. E desde 1986, enfrenta-se, no Brasil, de forma quase ininterrupta, epidemias de dengue (VALLE, PIMENTA, AGUIAR, 2016; QUEIROZ, 2016).

Portanto, a infestação de Ae. aegypti no Brasil tem crescido desde 1986 e os casos de dengue apresentaram grandes elevações em 1991, 1998, 2002, 2008, 2010, 2013 e 2015, ano em que ocorreram mais de 1,6 milhão de casos (GOMES, 2016).

A expansão geográfica de dengue e o aumento da incidência de casos têm sido frequentemente relacionados a fatores climáticos, como o aquecimento global e os fenômenos El Niño e La Niña. Alguns destes fenômenos influenciam na intensidade das chuvas e consequentemente na 
variabilidade da biodiversidade dos países que são acometidos por esses fenômenos (QUEIROZ, 2016).

O histórico de ações governamentais contra a dengue se inicia com o combate ao mosquito, como forma de prevenir doenças, tais como a febre amarela. Desde o início do século XX as campanhas focaram no combate aos criadouros onde o mosquito deposita seus ovos (GOMES, 2016).

Considerando a importância da doença e suas consequências para a saúde da população, os governos federal, estaduais e municipais tem destinado poucos recursos em políticas públicas de combate à dengue, como por exemplo, o Programa Nacional de Controle da Dengue (PNCD), implantado em 2002. Esse programa propõe mudanças na forma de controlar a doença, enfatizando a importância da adesão e mobilização social, bem como incentiva a atuação das pessoas como "sanitaristas" responsáveis pelo controle de potenciais criadouros (SILVA; MALLMANN; VASCONCELOS, 2015).

Atualmente, há o desafio de controlar, prever riscos, e reverter a situação que o Brasil enfrenta em relação às arboviroses endêmicas (Dengue, Chikungunya e o Zika vírus), principalmente se tratando de doenças que perpassam um ciclo onde a ação humana está diretamente relacionada (NETO, 2016).

Assim, a possibilidade de utilizar formas didáticas alternativas no processo de educação em saúde, demonstra um diferencial de expansão deste conceito dentro de uma lógica de saúde preventiva. Ou seja, a tendência da educação como uma alternativa de rompimento na lógica curativista em saúde, com a valorização da prevenção como essencial no controle da disseminação das epidemias associadas ao Ae. aegypti, em detrimento à cura após a doença já instalada, deve ser reconhecida pela sociedade civil como uma responsabilidade coletiva e pela sociedade acadêmica como uma forma de reconhecer a população como agentes transformadores, ativos, dotados de pleno conhecimento, e capazes de reverter o estado de saúde populacional (NETO, 2016).

\section{METODOLOGIA}

Para a realização desta pesquisa, realizou-se um levantamento bibliográfico em diferentes bases de dados, tais como artigos, guias, manuais e livros acerca das temáticas dengue e saúde pública, bem como de aspectos socioeconômicos e demográficos sobre a Microrregião de Anápolis, Goiás.

Em seguida foram coletados dados estatísticos da microrregião citada, junto ao Instituto Brasileiro de Geografia e Estatística - IBGE, visando a caracterização geral da mesma. Foram obtidos dados sobre a dengue junto ao sistema Extranet da Superintendência de Vigilância em Saúde da Secretaria de Estado da Saúde do Governo do Estado de Goiás - SES-GO, vinculado ao Banco de Dados do Sistema Único de Saúde - DATASUS.

Os dados obtidos referem-se ao total de casos (morbidade nas três classificações: Dengue Clássica, Febre Hemorrágica de Dengue e Dengue com complicações, registradas na Classificação Internacional de Doenças e Problemas Relacionados à Saúde - CID-10) anual por municípios da microrregião. Os dados trabalhados referem-se a todas as 52 semanas epidemiológicas entre os anos de 2010 e 2016. Esses dados foram analisados e trabalhados no software Microsoft Office Excel, em que realizou-se o cálculo do coeficiente de incidência para grupos populacionais de 100.000 habitantes (constante), permitindo assim, a comparação da incidência e impacto da doença sobre os municípios. O número de habitantes utilizado para cálculo do coeficiente foi o registrado no Censo de 2010 do IBGE (2010) para cada um dos municípios. Optou-se pela utilização dos dados do Censo por se mostrarem mais consolidados que as estimativas geradas posteriormente, ainda que se reconheça a dinâmica de mudança nos padrões demográficos nos últimos anos.

Após a geração dos coeficientes de incidência para cada um dos municípios, os dados foram espacializados, isto é, sobrepostos a base cartográfica da respectiva região, utilizando-se de procedimentos inerentes ao geoprocessamento, que segundo Barcellos (2006, p. 45), quando "[...] aplicado a questões de Saúde Coletiva permitem mapeamento de doenças, a avaliação de riscos, o planejamento de ações de saúde e a avaliação de redes de atenção".

Para a espacialização da incidência, foram definidas cinco classes de frequência, seguindo em parte intervalos definidos pela própria Organização Mundial da Saúde - OMS e pelo Ministério da Saúde. Essa metodologia, é denominada de "estratificação de dados" por Magalhães et al. (2006), e se apresenta conforme os grupos descritos abaixo: 
1- 0 - Sem registros;

2- Até 100,00 - Baixa incidência;

3- 100,01 até 300,00 - Média incidência;

4- 300,01 até1000,00 - Alta incidência;

5- Acima de 1000,01 - Altíssima incidência.

Os dados foram espacializados mediante uso do software ESRI ArcGIS 10.2, com aplicação da estratificação dos dados segundo metodologia citada anteriormente para base cartográfica obtida junto ao IBGE, gerando assim, mapas coropléticos.

\section{CARACTERIZAÇÃO DA ÁREA DE ESTUDO}

A Microrregião de Anápolis localiza-se no centro do Estado de Goiás (de acordo com Mapa 1), dispondo de uma área total de $8.311,93 \mathrm{Km}^{2}$. É composta por 20 municípios, sendo eles: Anápolis, Araçu, Brazabrantes, Campo Limpo de Goiás, Caturaí, Damolândia, Heitoraí, Inhumas, Itaberaí, Itaguari, Itaguaru, Itauçu, Jaraguá, Jesúpolis, Nova Veneza, Ouro Verde de Goiás, Petrolina de Goiás, Santa Rosa de Goiás, São Francisco de Goiás e Taquaral de Goiás (IBGE, 2016).

\section{Mapa 1 - Estado de Goiás: Microrregião de Anápolis}
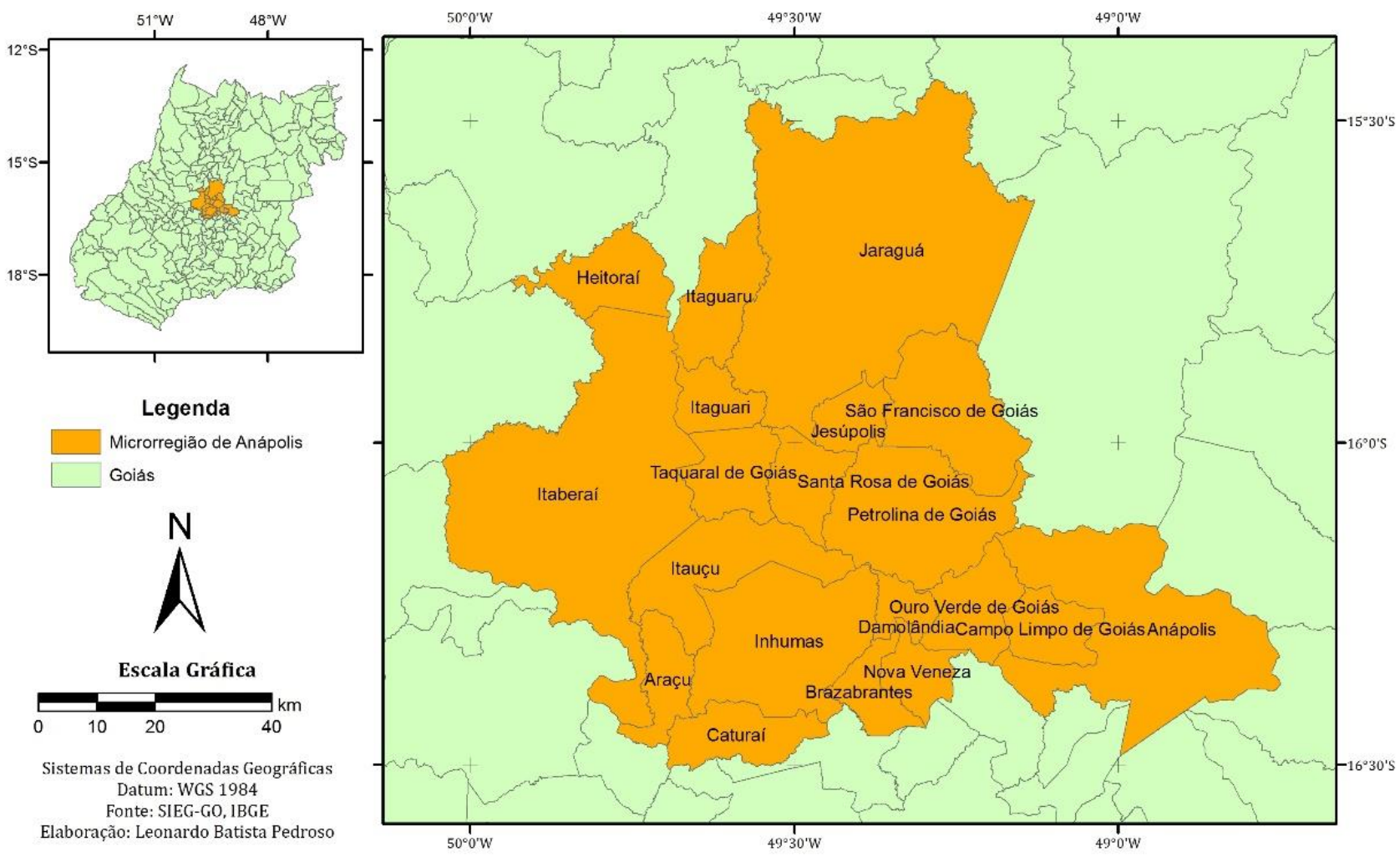

Fonte: SIEG-GO, IBGE, 2017.

Elaboração: PEDROSO, 2017.

A microrregião apresenta uma população estimada (IBGE, 2016) em 594.868 habitantes, com cerca de $92,73 \%$ destes habitando áreas urbanas e 7,26\% áreas rurais. Trata-se de uma área em pleno dinamismo de expansão demográfica e econômica, sobretudo em Anápolis, em grande parte relacionados à oferta de empregos em empresas no DAIA - Distrito Agroindustrial de Anápolis, bem 
como da potencialização de suas estruturas industriais e de serviços pela conclusão da Ferrovia Norte-Sul e a integração com a Ferrovia Centro Atlântica (OBSERVATÓRIO DO MUNDO DO TRABALHO, 2013).

\section{RESULTADOS E DISCUSSÕES}

A dengue se comportou de maneira distinta entre o intervalo que compreende os anos de $2010 \mathrm{e}$ 2016. A microrregião que é composta por 20 municípios chegou a apresentar 17.400 casos no ano de 2016.

Levando-se em consideração a população total regional de 540.220 habitantes, a região apresentou um coeficiente de incidência calculado em $3.220,9$ para grupos de 100.000 habitantes, valor superior ao limiar de risco determinado por órgãos de saúde, cujo limite é de 300 para 100.000 habitantes. O número absoluto de casos de dengue para a região pode ser observado mediante análise do Gráfico 1 , disposto a seguir.

Gráfico 1 - Número absoluto de casos de dengue, registrados na microrregião de Anápolis, GO, no período entre 2010 a 2016

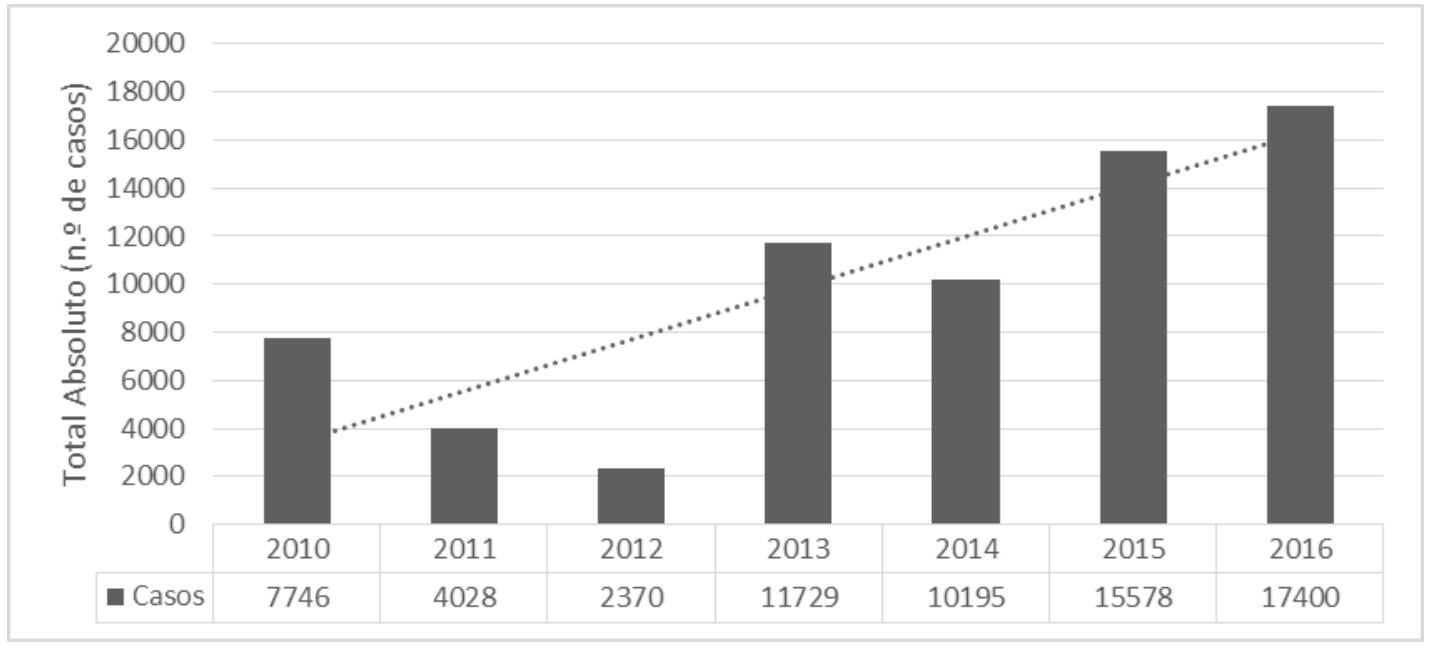

Fonte: SES-GO, 2010-2016.

Entre todos os anos, o ano de 2012 foi o que apresentou menor número de casos, somando 2.370 notificações, resultando em uma incidência de 438,7, também considerada alta. 2011 apresentou a segunda menor incidência, com 745,6, e 4.028 casos notificados. 2010 apresentou 7.746 notificações, resultando na terceira menor incidência do período analisado, com coeficiente de $1.433,8$

Os coeficientes para os demais anos, sendo eles os de 2013, 2014 e 2015 foram de 2.171,1, 1.887,1 e 2.883,6, respectivamente. Nota-se que durante todo o período analisado, os dados acusam situação epidêmica, isto é, com coeficientes muito acima dos limites considerados dentro do padrão de controle e/ou normalidade.

Da análise do Gráfico 1, pode-se depreender também que entre os anos de 2010, 2011 e 2012, o número absoluto de casos de dengue, na região em estudo, diminuiu. Tais números podem estar associados à redução vetorial por ações governamentais, bem como à imunização natural ao sorotipo viral circulante na região sobre a população exposta à períodos epidêmicos anteriores.

Nesses anos as ações de combate e as campanhas que orientaram a população com relação às formas de transmissões da doença, bem como, ações de erradicação do mosquito transmissor alcançaram parcialmente suas metas propostas. De outro lado, do ano de 2012 para 2013, houve um aumento de quase $500 \%$ no número de casos. Em que pese que em 2012, foi o ano de lançamento do PLANO ESTADUAL DE SAÚDE - PES 2012 - 2015, pelo Governo do Estado de Goiás (GOIÁS, 2012). 
Nos anos que se seguem, exceto com uma pequena diminuição em 2014, os números de casos somente aumentaram de forma significativa, até 2016, que apresentou o maior valor de coeficiente para o período estudado. Esses dados denotam que as políticas públicas de orientação da população para evitar a geração de criadouros do mosquito transmissor da doença, assim como os procedimentos de erradicação do mosquito adulto, não se mostraram eficazes.

Estudos realizados, identificaram que, as dificuldades na atuação dos trabalhadores em saúde denominados de Agentes de Controle de Vetores (ACV) e a pouca adesão da população ao Programa Nacional de Controle da Dengue (PNCD), com recusas da população às visitas domiciliares, por acreditarem que o controle e prevenção da dengue seriam atividades de importância menor, em relação a outros problemas que afetam a saúde, são fatores que podem diminuir a eficácia do programa de controle da dengue, com o consequente aumento do número de casos da doença (CHIARAVALLOTI-NETO, 2007 apud CESARINO et. al, 2014; GONÇALVES et. al, 2014).

De outro lado, os dados demonstram que entre os anos de 2010, 2011 e 2012, o número absoluto de casos de dengue, na região em estudo, apresentaram os menores valores. Tais números podem estar associados à redução vetorial por ações governamentais, bem como à imunização natural ao sorotipo viral circulante na região sobre a população exposta à períodos epidêmicos anteriores.

Nesses anos, as ações de combate e as campanhas que orientaram a população com relação às formas de transmissões da doença, bem como, ações de erradicação do mosquito transmissor alcançaram parcialmente suas metas propostas.

As tabelas a seguir permitem a visualização de três momentos distintos, verificados no gráfico anterior: biênio 2015-2016, que demonstra maior incidência de casos de dengue; biênio 2013-2014, que exibe valores médios, demonstrando determinada transição para aumento no número de casos; e o triênio 2010-2012, caracterizado pela menor incidência no período de estudo de dengue para a Microrregião de Anápolis.

A cidade de Campo Limpo, com a maior incidência, não registrou nenhum óbito no período em estudo, de acordo com os dados da superintendência de vigilância em saúde gerência de vigilância epidemiológica, no boletim semanal de dengue, estado de Goiás em 2010.

A maior cidade dessa microrregião, que é Anápolis, em 2010, teve o maior número de casos (Tabela 1). Apresentou a terceira maior quantidade de casos em relação ao estado de Goiás. Além disso foi a cidade onde ocorreu o maior número de óbitos, nesse período, de acordo com o Boletim da Dengue da VISA-GO (2010). Apesar de apresentar uma incidência muito menor que a cidade de Itaguari, por exemplo, apresentou cinco vezes mais óbitos.

Nota-se na Tabela 1, que a maioria dos municípios listados apresentaram coeficiente de incidência superior a 300 por 100.000 habitantes, indicando situação de surto epidêmico.

Em 2011, embora seja constatada redução significativa do número de casos, alguns municípios permaneceram com incidência alta, conforme visualizado na Tabela 1. Mesmo com a queda de 838 em 2010, para 84 notificações em 2011, o município Campo Limpo de Goiás apresentou a maior incidência $(1.345,9)$ da microrregião em 2011. Essa elevada incidência sugere situação de estado de surto epidêmico e, por permanecer nessa situação por mais de um ano, tal fato contempla-se enquanto um sério problema de saúde pública local.

Anápolis teve o maior número de notificações, com 3.396 casos contabilizados, porém ocupando segunda posição dentre as maiores incidências regionais, com 1.014,9 para 100.000 habitantes. Taquaral de Goiás, Brazabrantes, Nova Veneza, Itaberaí, Itaguari e Santa Rosa de Goiás, por apresentarem incidência superior a 300, também encontravam-se em situação alarmante.

O município de Anápolis ocupou o primeiro lugar em número de notificações e também no índice, com valores de 2.199 e 657,2, respectivamente. Todavia, ressalta-se que o valor representa uma redução em relação aos casos quantificados nos dois anos antecedentes. O total registrado em 2012 também apresenta situação de surto epidêmico.

Em 2012, de acordo com a Tabela 1, é possível constatar que a queda em relação ao número de notificações não acompanhou tendência nacional. Em capitais como Rio de Janeiro e Fortaleza, foram constatadas epidemias nos anos de 2011 e 2012, com índices superiores a 300 casos para 100.000 habitantes (GOMES et. al, 2015). 
Tabela 1 - Número de casos e Incidências de dengue no triênio, 2010 a 2012, nos municípios pertencentes a Microrregião de Anápolis, GO

\begin{tabular}{|c|c|c|c|c|c|c|c|c|}
\hline \multicolumn{3}{|c|}{2010} & \multicolumn{3}{|c|}{2011} & \multicolumn{3}{|c|}{2012} \\
\hline Município & Notificações & Incidência & Município & Notificações & Incidência & Município & Notificações & Incidência \\
\hline $\begin{array}{c}\text { Campo Limpo } \\
\text { de Goiás }\end{array}$ & 838 & 13427,3 & $\begin{array}{c}\text { Campo } \\
\text { Limpo de } \\
\text { Goiás }\end{array}$ & 84 & 1345,9 & Anápolis & 2199 & 657,2 \\
\hline Itaguaru & 243 & 4469,4 & Anápolis & 3396 & 1014,9 & $\begin{array}{l}\text { Taquaral } \\
\text { de Goiás }\end{array}$ & 13 & 367,1 \\
\hline Itaguari & 180 & 3988,5 & $\begin{array}{c}\text { Taquaral de } \\
\text { Goiás }\end{array}$ & 28 & 790,7 & $\begin{array}{l}\text { Campo } \\
\text { Limpo de } \\
\text { Goiás }\end{array}$ & 14 & 224,3 \\
\hline Anápolis & 5656 & 1690,3 & Brazabrantes & 23 & 711,6 & Itaguari & 8 & 177,3 \\
\hline Brazabrantes & 52 & 1608,9 & $\begin{array}{c}\text { Nova } \\
\text { Veneza }\end{array}$ & 48 & 590,5 & Caturaí & 8 & 170,7 \\
\hline Araçu & 45 & 1183,6 & Itaberaí & 146 & 412,8 & Jaraguá & 54 & 129,0 \\
\hline $\begin{array}{c}\text { Taquaral de } \\
\text { Goiás }\end{array}$ & 36 & 1016,7 & Itaguari & 18 & 398,8 & Araçu & 4 & 105,2 \\
\hline $\begin{array}{l}\text { Ouro Verde } \\
\text { de Goiás }\end{array}$ & 28 & 694,1 & $\begin{array}{l}\text { Santa Rosa } \\
\text { de Goiás }\end{array}$ & 10 & 343,8 & Inhumas & 47 & 97,4 \\
\hline Itauçu & 55 & 641,4 & Araçu & 11 & 289,3 & $\begin{array}{l}\text { Nova } \\
\text { Veneza }\end{array}$ & 6 & 73,8 \\
\hline Inhumas & 240 & 497,5 & Jaraguá & 116 & 277,0 & Heitoraí & 2 & 56,0 \\
\hline
\end{tabular}

Fonte: SES-GO, 2010-2012.

Taquaral de Goiás, embora tenha apresentado somente 13 casos notificados, também encontrou-se em situação de surto epidêmico, com índice de 367,1. Os demais municípios apresentaram valores abaixo deste limite.

No ano de 2012, cinco municípios não apresentaram notificações de dengue registradas no sistema do DATASUS, sendo eles: Jesúpolis, Damolândia, Itaguaru, Santa Rosa de Goiás e Brazabrantes. É importante frisar que a ausência de registros pode indicar status de subnotificação, isto é, casos não notificados em unidades de saúde.

Da análise da primeira tabela, pode-se depreender que as medidas na tentativa de diminuir os casos de dengue na região, mostraram-se parcialmente eficientes. Pois, pode-se observar que o número de casos na cidade de Anápolis, diminuíram significativamente, nesse período.

Bastos et. al, (2015) são peremptórios em afirmar que é fundamental adaptar o discurso de profilaxia de ocorrências de casos de dengue, de acordo com o público, a fim de haver real compreensão e aderência à conduta preconizada, em cada região, bem como nas cidades de Goiás.

Da análise da Tabela 2, constata-se que no ano de 2013, a cidade de Anápolis figurou novamente entre as maiores incidências regionais, e ocupou a segunda posição do total de vinte municípios, com índice de 2.606,9 e 8.723 casos notificados.

Sobre a dengue, de acordo com Tambellini e Miranda (2012, p. 76), "o mecanismo de emergência é a expansão do vetor, cujas forças motrizes (da emergência) são a urbanização, as condições precárias de moradia e o aquecimento global".

Desta forma, é possível inferir que Anápolis, por apresentar proeminentemente a maior população e maior densidade demográfica regional, dispõe de maior grau de vulnerabilidade à doença.

A grande circulação de pessoas, mercadorias e o adensamento populacional e de edificações contribui severamente para a proliferação do vetor transmissor da doença e para a prevalência da mesma em seu recorte espacial. Sabe-se que os problemas crônicos de infraestrutura e de planejamento urbano aumentam o potencial para perdas e danos ambientais, sociais e de saúde, dentre os quais esse quadro epidêmico de dengue (PEREIRA et al., 2014). 
Tabela 2 - Número de casos e Incidências de dengue no biênio, 2010 a 2012, nos municípios pertencentes a Microrregião de Anápolis, GO

\begin{tabular}{ccc|ccc}
\hline \multicolumn{3}{c}{$\mathbf{2 0 1 3}$} & & \multicolumn{3}{c}{$\mathbf{2 0 1 4}$} \\
\hline Município & Notificações & Incidência & Município & Notificações & Incidência \\
\hline Jaraguá & 1752 & 4184,4 & Itauçu & 395 & 4606,4 \\
Anápolis & 8723 & 2606,9 & Jesúpolis & 65 & 2826,1 \\
$\begin{array}{c}\text { Brazabrantes } \\
\text { Campo Limpo } \\
\text { de Goiás }\end{array}$ & 47 & 1454,2 & Caturaí & 129 & 2752,9 \\
Caturaí & 87 & 1394,0 & Anápolis & 7816 & 2335,8 \\
Itaberaí & 38 & 1301,7 & $\begin{array}{c}\text { Santa Rosa } \\
\text { de Goiás }\end{array}$ & 65 & 2234,4 \\
Nova Veneza & 69 & 1085,6 & $\begin{array}{c}\text { Itaguaru } \\
\text { Campo }\end{array}$ & 103 & 1894,4 \\
Damolândia & 22 & 848,8 & $\begin{array}{c}\text { Limpo de } \\
\text { Goiás }\end{array}$ & 113 & 1810,6 \\
Inhumas & 362 & 750,3 & $\begin{array}{c}\text { Taquaral de } \\
\text { Goiás }\end{array}$ & 56 & 1581,5 \\
Heitoraí & 23 & 644,1 & Jaraguáá & 734 & 1521,4 \\
\hline
\end{tabular}

Fonte: SES-GO, 2013-2014.

Jaraguá, embora não tenha apresentado número de casos que the ofertasse grande risco em anos anteriores, foi o que apresentou maior incidência regional, com 1.752 notificações e índice de 4.184,4. Trata-se da terceira maior população dentre os municípios da região, com 41.870 habitantes (IBGE, 2012), considerando em parte as considerações feitas para Anápolis, de acordo com Tabela 2.

O único município fora de situação epidêmica em 2013 foi Araçu, com índice de 157,8, calculado em cima das seis notificações registradas no respectivo ano.

Em 2014, a situação regional é agravada e nove dos 12 municípios apresentaram altíssima incidência, isto é, com coeficientes acima de 1000 casos para cada 100.000 habitantes. Foram notificados 10.195 casos neste ano. As maiores incidências são também observadas na Tabela 2.

O ano de 2014 apresentou uma particularidade. Embora municípios como Anápolis e Campo Limpo de Goiás estejam listados dentre os de maior incidência, o topo é ocupado por Itauçu e Jesúpolis, que nos anos anteriores, não se mostraram com números tão problemáticos. Estes apresentaram $395 \mathrm{e}$ 65 casos, com índices calculados em 4.606,4 e 2.826,1, respectivamente.

Em sequência, alocam-se os municípios de Caturaí e Anápolis com coeficientes de incidência calculado em 2.752,9 e 2.335,8, respectivamente. De todo o recorte temporal analisado, este foi o maior índice para o município de Caturaí, registrando 129 casos para uma população de 4.686 habitantes.

Apenas dois municípios ficaram abaixo do limiar de epidemia, sendo eles: Petrolina de Goiás e São Francisco de Goiás, com índices em 243,1 e 179,7, demonstrando que a doença também não se mostrou sob controle na região durante o ano de 2014.

O número de notificações de dengue voltou a subir no Estado de Goiás em 2015, de 124.764 para 189.421, representando $53,72 \%$ de aumento em relação à 2014. Não obstante, este aumento se fez presente também na Microrregião de Anápolis, resultando na soma de 15.578 casos (SES-GO, 2015).

O terceiro período de análise constitui-se pelo biênio 2015-2016, onde verificou-se aumento no número de notificações. De acordo com a Tabela 3, apresentada a seguir, é possível constatar que todos os municípios listados apresentaram índices altíssimos: 
Tabela 3 - Número de casos e Incidências de dengue no biênio, 2015 a 2016, nos municípios pertencentes a Microrregião de Anápolis, GO

\begin{tabular}{|c|c|c|c|c|c|}
\hline \multicolumn{3}{|c|}{2015} & \multicolumn{3}{|c|}{2016} \\
\hline Município & Notificações & Incidência & Município & Notificações & Incidência \\
\hline Itaguaru & 479 & 8810,0 & Anápolis & 16032 & 4791,2 \\
\hline Damolândia & 132 & 4805,2 & Nova Veneza & 168 & 2066,7 \\
\hline Nova Veneza & 348 & 4281,0 & Itaguaru & 98 & 1802,5 \\
\hline $\begin{array}{l}\text { Taquaral de } \\
\text { Goiás }\end{array}$ & 121 & 3417,1 & Itauçu & 148 & 1725,9 \\
\hline Anápolis & 11421 & 3413,2 & Caturaí & 74 & 1579,2 \\
\hline $\begin{array}{l}\text { Campo Limpo } \\
\text { de Goiás }\end{array}$ & 198 & 3172,6 & Brazabrantes & 39 & 1206,7 \\
\hline $\begin{array}{c}\text { Ouro Verde de } \\
\text { Goiás }\end{array}$ & 126 & 3123,5 & Damolândia & 29 & 1055,7 \\
\hline Heitoraí & 90 & 2520,3 & $\begin{array}{l}\text { Ouro Verde de } \\
\text { Goiás }\end{array}$ & 39 & 966,8 \\
\hline Itaberaí & 877 & 2479,4 & $\begin{array}{l}\text { Campo Limpo } \\
\text { de Goiás }\end{array}$ & 47 & 753,1 \\
\hline Caturaí & 102 & 2176,7 & Itaguari & 32 & 709,1 \\
\hline
\end{tabular}

Fonte: SES-GO, 2015-2016.

Itaguaru, Damolândia e Nova Veneza foram os municípios da microrregião com maior incidência, com índices em 8.810,0, 4.805,2 e 4.281,0, respectivamente. Taquaral de Goiás, Anápolis e Campo Limpo de Goiás também, na sequência, também já constavam nas listas de maior incidência dos anos anteriores (Tabelas 1 e 2), o que demonstra ineficiência no que diz respeito ao controle da doença em seu território.

Considerando-se a maior cidade da microrregião em estudo, o aumento do número de casos na cidade de Anápolis, pode ser explicado, até mesmo por ausência da utilização de diversas ferramentas estratégicas para a prevenção e promoção da Saúde nas regiões endêmicas, conforme estudos de Costa et al. (2014) e de Garcia et al. (2016). Dos 17.400 casos da região, Anápolis, sozinha apresentou 16.032 casos, o que corresponde a $92,13 \%$ dos casos. A incidência para o período foi taxada em 4.791,2, sendo este valor bem acima do limiar epidêmico.

Em 2016, último ano de análise, foram notificados 17.400 casos, sendo este o maior número entre os anos de 2010 e 2016. Contudo, estes foram mais distribuídos nos municípios da microrregião do que em 2015, resultando em menores índices do que no ano citado.

Assim como em 2014, Petrolina de Goiás manteve-se abaixo do limite epidêmico, registrando 291,7 em 2015. Anápolis, por sua vez, apresentou o seu segundo maior índice do recorte temporal analisado, com 3.413,2 e 11.421 casos notificados.

Ainda é necessário ressaltar que o Governo do Estado de Goiás criou um Comitê Estadual de Mobilização Contra Dengue, que realizaram ações de prevenção contra a doença no campo da gestão e do planejamento, entre os anos de 2012 e 2014, e que mesmo assim o número de casos aumentou durante este intervalo (CANÇADO et al., 2016).

Ou seja, estas ações precisam ser fortalecidas e implementadas dentro do Comitê, com o empoderamento e a responsabilização de todos os representantes, para que não se observe apenas ações teóricas, mas, efetivas em todos os agentes envolvidos no contexto da dengue (CANÇADO et al., 2016). Toda análise da incidência realizada para o período entre os anos de 2010 e 2016 para a Microrregião de Anápolis pode ser endossada mediante análise do conjunto disposto no Mapa 2.

Há de se ressaltar que em 2016 três municípios apresentaram incidência menor que 300 para 100.000 habitantes, sendo eles: Jesúpolis, Petrolina de Goiás e São Francisco de Goiás, com índices calculados em 43,47, 97,24 e 245,09, respectivamente. Dos citados, Petrolina de Goiás é o que dispõe de situação menos preocupante se analisado todo período. Em apenas um ano do intervalo, apresentou dados acima do limite de epidemia. 
Mapa 2 - Microrregião de Anápolis: Espacialização do coeficiente de incidência de dengue, 2010-2016
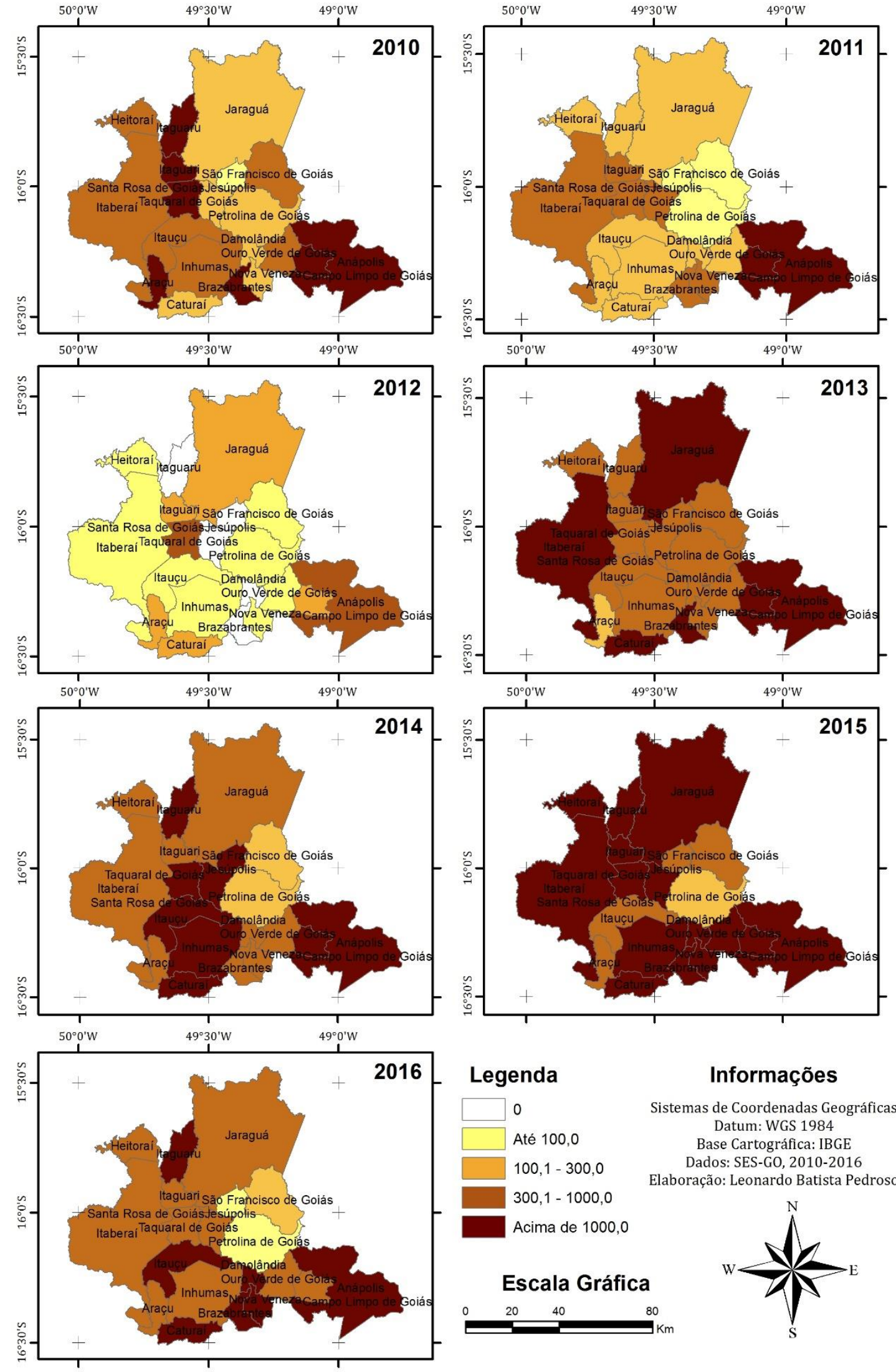

\section{Informações}

Sistemas de Coordenadas Geográficas Datum: WGS 1984

Base Cartográfica: IBGE

Dados: SES-GO, 2010-2016
Elaboração: Leonardo Batista Pedroso

\section{Escala Gráfica}
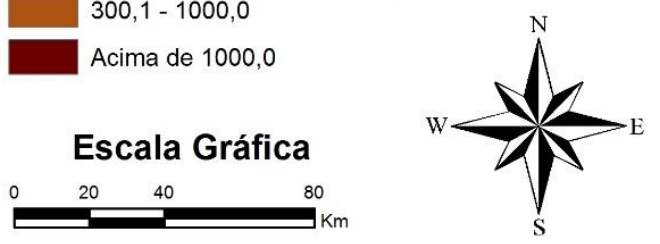

Fonte: SES-GO, 2010-2016.

Elaboração: PEDROSO, 2017. 
Para se manter abaixo do limiar epidêmico e demonstrar clareza e veracidade nos dados de agravos de notificação, há que se destacar a importância do estímulo à educação continuada no que diz respeito ao preenchimento das fichas de notificação compulsória, para que se possa realmente apresentar a realidade da dengue em todas as regiões endêmicas e assim promover ações efetivas de combate à dengue e ao mosquito transmissor (CARNEIRO et al., 2015; QUEIROZ, 2016). Além de tais medidas de cunho educacional, faz-se de suma importância a manutenção de pesquisas laboratoriais e biotecnológicas, no que tange o desenvolvimento de vacinas e amplo conhecimento viral, para os diferentes sorotipos, bem como o trabalho de vigilância e manejo ambiental.

Para que as ações de controle vetorial apresentem êxito, é importante dispor de um conjunto de metodologias com alta capacidade de complementação, ou seja, um manejo integrado que, mesmo apresentando falhas pontuais, seja capaz de se adaptar à realidade local e assim, tornar-se eficiente em longos períodos de tempo (OPAS, 1995).

Nesse sentido, saber da medida da carga financeira e social de uma doença é uma informação que pode ser útil, para que a gestão em saúde e ambiente possa decidir onde e como aplicar seus recursos, e que justifica a necessidade de investimento e fortalecimento do setor de Vigilância em Saúde, que é fundamental para o controle de surtos e minimização dos efeitos de desastres sobre a saúde (Pereira et al, 2014).

Contudo, o que se constata na realidade é o emprego de técnicas que não resolvem o problema; apenas atenuam. Muitos municípios limitam-se ao emprego de inseticidas químicos grupos dos organoclorados, organofosforados, carbamatos/piretróides (BRAGA, VALLE, 2007). Mesmo com todo o aparato químico, a resistência a inseticidas tem sido detectada em praticamente todas as classes, propiciando a re-emergência de doenças transmitidas por vetores (BROGDON, MCALLISTER, 1998).

Desta forma, é fundamental que o poder público possibilite o diálogo com a população, buscando vias adequadas à promoção da saúde e ao bem-estar, instruindo a sociedade no desenvolvimento conjunto de ações que possibilitem o enfrentamento com a doença.

\section{CONSIDERAÇÕES FINAIS}

A análise da situação da dengue na Microrregião de Anápolis revela um grave problema de saúde pública para grande parte dos municípios presentes na área de estudo. De todos os municípios da região, Anápolis, juntamente com Taquaral de Goiás, foram os únicos que apresentaram status de epidemia durante todos os anos que compreendem o período entre 2010 e 2016 . Ressalta-se que, no caso de Anápolis, o índice de urbanização se mostra como fator preponderante, uma vez que a dengue se mostra como uma doença que se desenvolve nessas condições, dadas às condições de adaptabilidade e desenvolvimento vetorial.

A situação de manutenção de estado epidêmico dos municípios por mais de dois anos consecutivos doença durante o período analisado é um aspecto importante a ser observado por parte dos gestores de saúde, uma vez que representa sério risco em relação à saúde pública. Os altíssimos índices registrados endossam a necessidade de reavaliar políticas e métodos de controle da doença e do vetor.

Sabe-se que o modelo tradicional de controle da dengue no Brasil elegeu como um dos seus principais eixos estratégicos a participação popular. Na prática, essa estratégia tem se mostrado incapaz de promover o envolvimento e a mudança de comportamento da população, considerados essenciais para o controle dessa endemia (CHIARAVALLOTI-NETO, 2007 apud GONÇALVES et al. (2015).

Cançado et al. (2016), afirmam de forma incontroversa, que é fundamental a elaboração de programas de prevenção e controle da dengue que sejam pautados na gestão e no planejamento. Deve haver o envolvimento articulado entre educação, saneamento, cultura, transporte, turismo, segurança pública e meio ambiente, com o envolvimento de todos os setores da sociedade para que resultados como estes não ocorram.

Assim sendo, é possível concluir que faz-se necessário o monitoramento do número de casos e da incidência sobre determinado recorte territorial, a fim de se evitar situações de descontrole que possam ocasionar problemas de saúde pública. A utilização de ferramentas estatísticas e de análise espacial, nesta perspectiva, contempla-se enquanto uma ferramenta indispensável aos gestores em saúde. 


\section{REFERÊNCIAS}

BASTOS, L.K.; BASTOS, K.K.; VIGGIANO, G.F.; VILLELA, E.F.M. Dengue em foco: um relato de experiência com crianças de escolas municipais. Revista de Patologia Tropical, Goiânia, v. 44 n. 1, p.87, set., 2015.

BRAGA, I. A.; VALLE, D. Aedes aegypti: inseticidas, mecanismos de ação e resistência. Epidemiol. Serv. Saúde, Brasília, v.16, n.4, p.279-293, out./dez. 2007.

BRASIL. Ministério da Saúde. Secretaria de Vigilância em Saúde. Monitoramento dos casos de dengue, febre de chikungunya e febre pelo vírus Zika até a Semana Epidemiológica 52, 2015.

Boletim Epidemiológico, v.47, n.3, s./p., 2016.

BRASIL. Ministério da Saúde. Tudo que você precisa saber sobre dengue. Disponível em: < https://www.dengue.org.br/Site_da_Dengue_www_dengue_org_br.pdf>. Acesso em: 10 nov. 2016.

BROGDON, W. G.; MCALLISTER J.C. Insecticide resistance and vector control. Emerging Infectious Diseases, v.4, n.4, p.605-613, 1998. https://doi.org/10.3201/eid0404.980410

CANÇADO, M. M.; OLIVEIRA, E. S. F.; BARBOSA, M. A.; TEIXEIRA, R. A. G.; SOUZA, D. C. D. N. O processo de gestão no plano de combate à dengue. 1\% Infecto Centro Oeste (Resumo dos trabalhos científicos), 2016. Disponível em: <www.infectocentrooeste.com.br> Acesso em 12 jan. 2017.

CARNEIRO B. V.; CASTANHO D. L. M.; ROSAS W.P.; MENEZES A.I.C.; PIRES L.L. Notificação Compulsória de Dengue em Hospital terciário militar - análise da vigilância em saúde. Revista de Medicina e Saúde de Brasília, v.4. n.2, p.144-56, 2015.

CESARINO, M. B.; DIBO, M. R.; IANNI, A. M. Z.; VICENTINI, M. E.; FERRAZ, A. A.; CHIARAVALLOTI-NETO, F. A difícil interface controle de vetores - atenção básica: inserção dos agentes de controle de vetores da dengue junto às equipes de saúde das unidades básicas no município de São José do Rio Preto, SP. Saúde Soc., São Paulo, v. 23, n. 3, p. 1018-1032, Set., 2014.

CHIARAVALLOTI-NETO, F.; BAGLINI, V.; CESARINO, M. B.; FAVARO, E. A.; MONDINI, A.; FERREIRA, A. C.; DIBO, M. R.; BARBOSA, A. A. C.; FERRAZ, A. A. O programa do controle do dengue em São José do Rio Preto, São Paulo, Brasil: dificuldades para a atuação dos agentes e adesão da população. Caderno de Saúde Pública, v. 23, n. 7, p. 1656-1664, 2007.

https://doi.org/10.1590/S0102-311X2007000700017

COSTA, C. A.; PETRUCIO, W. S.; RODRIGUES, P. M. A.; LAGES, R. O.; WEN, C. L. Efetividade das práticas de Teleducação por Webconferência no combate à dengue no Estado do Amazonas, Brasil. Journal Health Informatics, v. 6, n.1, p.15-18, jan./mar., 2014.

GARCIA, M. M.; ÁVILA, J. P.; FERREIRA, B. C. A.; DE CASTRO, G. S.; CLEMENTINO, L. K. C.; BOMFIM, R. C. F.; MILKI, M. V. Projeto Xerifes do aedes. Projeto xerifes do aedes. (Resumo dos trabalhos científicos), 2016. Disponível em: <www.infectocentrooeste.com.br>. Acesso em 12 jan. 2017.

GOIÁS. Secretaria de Estado da Saúde. Plano Estadual de Saúde - PES - 2012 -2015. Assessoria técnica do gabinete do secretário, 2012. Disponível em:

<www.sgc.goias.gov.br/upload/links/arq_944_planoestadualdesaude2012-2015.pdf>. Acesso em: 12 jan. 2017.

GOMES, F. B. C. Aedes aegypti - (Estudo Técnico). Consultoria Legislativa, Brasília (Distrito Federal), Câmara dos Deputados, 12 p, 2016. Disponível em: <www2.camara.leg.br/documentos-epesquisa/fiquePorDentro/temas/aedes- aegypti/>. Acesso em: 29 dez. 2016.

GOMES, K. W. L.; MESQUITA, L. P. S.; CAPRARA, A.; BENEVIDES, B. S.; GONÇALVES, R. P. Organização do processo de trabalho no manejo da dengue em uma capital do Nordeste. Saúde Debate, Rio de Janeiro, v.39, n.105, p.561-569, abr./jun., 2015.

INSTITUTO BRASILEIRO DE GEOGRAFIA E ESTATÍSTICA - IBGE (Brasil). Censo Demográfico 2010 - Características Gerais da População. Rio de Janeiro: IBGE, 2012.

INSTITUTO BRASILEIRO DE GEOGRAFIA E ESTATÍSTICA - IBGE (Brasil). Dados censitários de Municípios de Goiás. Disponível em: <http://www.cidades.ibge.gov.br>. Acesso em: 21 dez. 2016. 
MAGALHÃES, M. A. F. M. et al. Sistemas de Informações Geográficas em saúde. In.: SANTOS, S. M.; BARCELLOS, C. (Org.). Abordagens espaciais na saúde pública. Brasília: Ministério da Saúde, 2006. p. 43-81.

MENDONÇA, F. A.; SOUZA, A. V.; DUTRA, D. A. Saúde Pública, Urbanização e Dengue no Brasil. Sociedade \& Natureza, Uberlândia, v.21, n.3, dez., 2009.

NETO, V. L. S.; Elaboração e implementação de ferramenta educativa com ênfase na dengue, zika e chikungunya: relato de experiência. Revista Extendere, Natal, n.1, v. 4, p.9-18, jan./ jun., 2016.

OBSERVATÓRIO DO MUNDO DO TRABALHO. Estudos Microrregionais: Estudos e pesquisas econômicas, sociais e educacionais sobre as microrregiões do Estado de Goiás - Microrregião de Anápolis. Goiânia: IFG, 2013. 53 p.

ORGANIZACIÓN PANAMERICANA DE LA SALUD - OPAS. Dengue y dengue hemorrágico en las Américas: guías para su prevención y control. Washington, DC: Organización Panamericana de la Salud, 1995.

PEDROSO, L. B.; MENDES, P. C.; MOURA, G. G. Ocorrência e distribuição espacial da dengue no Triângulo Mineiro e Alto Paranaíba. Caderno Prudentino de Geografia. Presidente Prudente, n.34, v.2, p.120-134, ago./dez., 2012.

PEREIRA, Carlos Alexandre Rodrigues et al. Avaliação econômica dos casos de Dengue atribuídos ao desastre de 2011 em Nova Friburgo (RJ), Brasil. Ciênc. saúde coletiva, Rio de Janeiro, v.19, n.9, p. 3693-3704, set., 2014.

QUEIROZ, R. E. Dengue grave no Brasil Central: aspectos clínicos e epidemiológicos. 2016. 78 f. Dissertação (Mestrado em Atenção à Saúde) - Programa de Pós-Graduação em Atenção à Saúde, Coordenação de Pós-Graduação Stricto Sensu, Pontifícia Universidade Católica de Goiás, Goiânia, 2016.

SECRETARIA DE ESTADO DA SAÚDE DE GOIÁS - SES-GO. Histórico anual e casos parciais de dengue em Goiás, 2015. Disponível em: <http://extranet.saude.go.gov.br/public/dengue.html>.

Acesso em: 21 dez. 2016.

SECRETARIA DE ESTADO DA SAÚDE DE GOIÁS - SES-GO. Casos notificados de dengue em Goiás, 2010-2016. Disponível em: <http://extranet.saude.go.gov.br/public/dengue.html>. Acesso em: 12 jan. 2017.

SEIDL, E. M. F.; ZANNON, C. M. L. C. Qualidade de vida e saúde: aspectos conceituais e metodológicos. Cadernos de Saúde Pública, Rio de Janeiro, v.20, n.2, p.580-588, mar./abr., 2004.

SILVA, I. B.; MALLMANN, D. G.; VASCONCELOS, E. M. R. Estratégias de combate à dengue através da educação em saúde: uma revisão integrativa. Saúde, Santa Maria, v.41, n.2, p.27-34, 2015.

https://doi.org/10.5902/2236583410955

SOUZA, M. L. Mudar a cidade: uma introdução crítica ao planejamento e à gestão urbanos. 5.ed. Rio de Janeiro: Bertrand Brasil, 2008. 560p.

TAMBELLINI, A. T.; MIRANDA, A. C. Desenvolvimento, trabalho, saúde e meio ambiente. Rio de Janeiro: CEBES, 2012. $171 \mathrm{p}$.

VALLE, D.; PIMENTA, D. N.; AGUIAR, R. Zika, dengue e chikungunya: desafios e questões.

Epidemiol. Serv. Saúde, Brasília, v. 25, n.2, p.419-422, abr./jun., 2016.

VIANA, D.V. IGNOTTI, E. A ocorrência da dengue e variações meteorológicas no Brasil: revisão sistemática. Rev. Bras. Epidemiol. v.16, n.2, p.240-56, 2013. https://doi.org/10.1590/S1415790X2013000200002

WORLD HEALTH ORGANIZATION - WHO. 2012-2010 Global strategy for dengue prevention and control. Geneva: WHO, 2012. 43p.

ZIONI, F.; WESTPHAL, M. F. O enfoque dos determinantes sociais de saúde sob o ponto de vista da Teoria Social. Saúde e Sociedade, São Paulo, v.16, n.3, p.26-34, set./dez., 2007.

https://doi.org/10.1590/S0104-12902007000300004 